Madrygal. Revista de Estudios Gallegos

ISSN: 1138-9664

\title{
Antón Santamarina: o lingüista esperado, o lingüista necesario nos anos da Posguerra. Unha breve incursión nas orixes do filólogo ${ }^{1}$
}

Xesús Alonso Montero

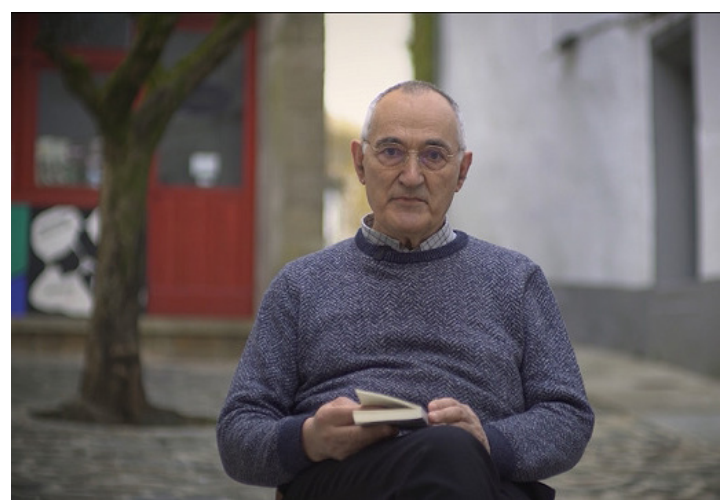

San Martín de Suarna, aldea do norte da provincia de Lugo, nas terras estúrdigas da Fonsagrada, é a patria de Antón Santamarina Fernández, desde hai décadas catedrático de Lingüística Románica desta Universidade. Xa antes de ser profesor titular desa disciplina, en 1975, era autor de importantes traballos relacionados coa gramática, co léxico, coa sociolingüística, coa onomástica, coa fonética, coa historia e co ensino do galego. Unha parte destes traballos, nomeadamente os relacionados co ensino da lingua galega, son traballos redactados coa colaboración doutros lingüistas novos. Penso, dun xeito especial, en Galego 1 (1971), Galego 2 (1972) e Galego 3 (1974). Creo non faltar ó respecto de ningún colaborador, se afirmo que, nestes tres manuais, pioneiros no xénero e tan eficaces, é moi significativa a man de Antón Santamarina, consecuencia do seu saber e do seu compromiso. Cando se redacte a inxente bibliografía de Antón con criterios non habituais, asomarémonos a obras colectivas onde o seu nome debería ser o principal e, mesmo, a obras de autor individual onde as achegas ou suxestións do profesor Santamarina merecen algo máis, moito máis, que unha nota de gratitude. Non hai caso. Antón pertence a unha familia rara, case inexistente, de intelectuais: a daqueles que non procuran a foto, que non reclaman estaren na punta da póla. Antón, aínda que quixese, non sabe darse pote.

Case se pode dicir - ou sen case- que, en Antón Santamarina, a vaidade non conta. Conta a obra, o traballo ben feito, o compromiso coa causa, neste caso, coa causa da lingua; por conseguinte, coa causa do país. Nesta ausencia de vaidade lembra, claramente, o proceder intelectual de quen foi, fóra das aulas, un dos seus grandes mestres: Ramón Piñeiro (sobre o discurso de ingreso de Piñeiro na Real Academia Galega, de tema lingüístico, versou o de Antón cando, trinta anos despois, ingresou na mesma Academia). Quen queira ter unha idea bastante completa do labor filolóxico do noso homenaxeado, lea o traballo do profesor Francisco Fernández Rei titulado "Antón Santamarina: unha vida de xenerosa entrega á construción e á dignificación da Patria da Lingua". Figura como pórtico do volume Homenaxe a Antón Santamarina publicado pola Universidade de Santiago de Compostela no ano 2008,

\footnotetext{
"Laudatio" lida no Paraninfo da Universidade de Santiago de Compostela no III Congreso Internacional de Lingüística Histórica (27-30 de xullo de 2015). Sobre o outro lingüista homenaxeado, Ramón Lorenzo, foi o profesor lisboeta Ivo Castro quen fixo a "laudatio". Crédito da imaxe: http:/www.crtvg.es/tvg/a-carta/anton-santamarina.
} 
e está constituído por trinta e oito páxinas esclarecedoras dignas do homenaxeado.

Xa aquí, eu vou facer unha incursión, fundamentalmente, na xénese do lingüista Antón Santamarina, tarefa na que me serán de moita utilidade dúas páxinas do traballo de Fernández Rei. Outros datos serán da miña minerva e, nalgún caso, da miña experiencia.

Permítanme, pois, esta pregunta maiúscula: como naceu Antón Santamarina para a Lingüística galega?

Viaxen comigo, miñas donas e meus señores, ás terras estúrdigas da Fonsagrada, concretamente á aldea de San Martín de Suarna. A aldea, en 1946, o ano do noso periplo, conta cuns veciños, en boa parte da clase socioeconómica dos celeireiros, xentes de precario pasar. $\mathrm{Na}$ aldea había algunhas casas moi acomodadas e de certo aquel histórico na que os seus vellos moradores tiñan dereito ó "don", que os veciños acataban. Nesta estamentoloxía había algunhas familias intermedias que, sen pasaren larotas e privacións, como os celeireiros, non posuían os recursos e comodidades das do "don"; é o caso da Casa da Iglesias, do avó paterno de Antón, a quen onte coma hoxe, parentes e veciños chaman Tocho, o hipocorístico Tocho.

Viaxen, pois, comigo, a aquela aldea de San Martín de Suarna. É o 18 de febreiro de 1946, data na que o Tocho cumpre catro anos. Ese día a nai bota un chourizo máis no pote e fai unhas lambetadas como as de había un ano. Á noite, o avó agasalla ó neto coa lectura dun poema en galego, xa lido, á luz do candil, noutras noites de inverno. Trátase d" "A Virxe do Cristal" de Curros Enríquez, unha lenda mariánica que o avó, home, por certo, moi relixioso, le con fruición, que transmite ó neto, engaiolado cos versos e co milagre, e entristecido polo final dos namorados. O Tocho, que aínda non vai á escola, non sabe ler, pero ten boa memoria e xa recorda algúns versos de recitais anteriores.

O 18 de febreiro de 1950 o Tocho cumpre 8 anos e na Casa da Iglesia volve haber festa de pote e festa literaria. O Tocho xa sabe ler e escribir e xa sabe, do libro de Curros Enríquez, o que non sabía había pouco. Sabe que
"A Virxe do Cristal" é unha parte dun libro no que hai moitos outros poemas, todos eles -ou case todos- de contido e intención moi diferentes. Titúlase Aires da miña terra e nel hai versos furibundos contra os curas, contra os abusos da Igrexa e a favor dos sufridos campesiños de Galicia (dez anos despois o Tocho, xa alumno do instituto de Lugo, oiríalle dicir a un profesor: "Curros Enríquez foi, quizais, o poeta civil, no século XIX, que mellor afiou a fouce da denuncia social e a da solidariedade co proletariado rural").

Pois ben, o exemplar de Aires da miña terra, moi raído e afumado, estaba agochado, pois, como o Antón intuía, era un libro moi mal visto polas autoridades da época, non só polo bispo e polos curas ${ }^{2}$.

Ese día, 18 de febreiro de 1950, Antón está sentado, ó pé do lume, á beira do seu avó, de seus pais e duns veciños de confianza, entre eles un mozo moi reflexivo, David Álvarez Carballido, que aínda vive hoxe en San Martín $^{3}$. Os de mellor oficio len poesías do libro: o avó, coma sempre, versos d"“A Virxe do Cristal"; un veciño moi volteriano, "Mirando ó chau"; unha muller que cursara un ano de bacharelato, "Na morte de miña nai", e o tal David, "Nouturnio", no que Antón batía con palabras como "tellas" e "bacelos", inexistentes no seu falar fonsagradés. Antón estaba verdadeiramente engaiolado: o poeta, que abordaba cousas tan distintas, facíao, cun xeito conmovedor, na fala que estaba ausente dos libros da escola e que subestimaban con rexoubas os señoritos da Vila.

$\mathrm{Na}$ Casa da Iglesia había unha pequena biblioteca: os libros que remitían desde Estados Unidos, con moitas cautelas, os tíos Enrique e Leonardo Santamarina, os dous profesores universitarios naquel país. Leonardo chegara a el, exiliado, en 1939, despois de loitar na España republicana os tres anos da guerra pluscuamcivil. En canto a Enrique, profesor nunha Facultade de Veterinaria, había pouco que chegara ós Estados Unidos despois de bastantes problemas en Galicia como activo antifranquista na loita clandestina. Chovía sobre

2 As noticias sobre este exemplar de Aires da miña terra (e dos seus lectores e oidores) proceden do traballo do propio Antón Santamarina “A familia Santamarina. Crónica de guerra e de posguerra”, Guieiros, Guitiriz, 5, 1999.

3 A este veciño, axiña exemplar cidadán e militante, gravoulle Antón, nos últimos anos, horas e horas de conversas que están na base do libro Memorias dun loitador antifranquista. O testemuño do comunista David Álvarez Carvallido, Santiago, Alvarellos, 2018. O volume contén, entre outras informacións complementarias, un prólogo do propio Santamarina e outro meu. 
mollado, pois na casa de Antón deixaran a súa impronta os libros deixados polo tío avó Manuel, que fora mestre, e, sobre todo, por outro tío avó, zoqueiro de oficio, que era librepensador e lector do ideólogo anarquista Kropotkin.

Antón, que foi estudante en Lugo entre 1953 e 1961, nas vacacións consultaba, conmovido, os libros e as revistas que os tíos republicanos e galeguistas remitían desde o seu exilio, e algunhas noites, con xente de confianza, exhumaban o exemplar de Aires da miña terra, cada vez máis afumado, e lían, coa fruición de sempre, os versos do gran Curros. Antón xa sabe que o seu destino profesional son as Letras, e, dentro desta carreira, o estudo daqueles saberes que lle expliquen qué significa a anomalía, a anormalidade social do idioma galego, e, se for posible, en que consistiría un proceso axeitado de normalización.

Do seu tío Leonardo, licenciado en Filosofía e Letras, non alleo á Filosofía e amigo de don Tomás Navarro Tomás, recibe bibliografía e asesoría neste sentido, e supoño que foi el quen o informou de que a súa aldea e outras moitas da comarca foron investigadas por un dialectólogo da escola de Hamburgo, Walter Ebeling, en 1928, 1929 e 1933 (os resultados foron publicados na revista Volkstum und Kultur der Romanem). Por se fose pouco, Antón vaise poder matricular no curso de 1963-1964 en Filoloxía Románica, o ano no que se inaugurou esta especialildade na vella Facultade de Filosofía e Letras de Compostela. Anos antes, alumnos con semellantes inquedanzas (é o meu caso), tivemos que emigrar a predios universitarios extragalegos. Tamén o fixo, en 1957, un dos eminentes lingüistas hoxe homenaxeados, o profesor Ramón Lorenzo, que cursou a especialidade, coma min, na Universidade Central (Madrid).

No curso 1960-1961, Antón Santamarina, estudante responsable e xa un consumado letraferido no Instituto masculino de Lugo, vai afortalar a súa perspectiva filolóxica no Preuniversitario, concretamente nas clases de Latín, de Amable Veiga Arias, e de Grego, de Joan Vaqué Jordi, ós que lembra sempre con inmensa gratitude. Nese preuniversitario, o catedrático de Literatura era eu, encargado de explicar, por decreto ministerial, a Fábula de Polifemo y Galatea, esa marabilla verbal de don Luís de Góngora, exemplo máximo, por outra parte, da Literatura de evasión. Cónstame que Antón, candidato a gran filólogo, memorizou as 63 oitavas reais, ou sexa, os 504 hendecasílabos de que constaba aquel maxistral artefacto culterano. Por certo, a Fábula suscitou un libro de texto admirable, obra de Dámaso Alonso, que era o que eu explicaba e os bos alumnos sabían.

Daquela estaba de moda o social-realismo de Alfonso Sastre, Armando López Salinas, Blas de Otero, Gabriel Celaya e moitos outros, e o propio Antón Santamarina ten recordado que nas miñas clases, sen deixar eu de tributar a miña admiración inmensa ó talento verbal e poético de Góngora, advertía ós alumnos que o escritor tiña que comprometerse e non evadirse. Un día, á saída da clase, Antón ofreceume unha revista cun artigo en galego, do seu tío Enrique, sobre a morriña, no que citaba a Curros. Días despois, comentándoo, aclareille que a obra poética de Curros Enríquez era un caso claro de literatura antiescapista, de literatura coas raíces na vida social e nos seus conflitos, unha literatura comprometida, como quería Sartre, que eu tanto citaba: comprometi$\mathrm{da}$, por se fose pouco, coas xentes que padecen a historia (que é unha frase de Camus).

A vida profesional de Antón Santamarina non foi, exactamente polos vieiros da Literatura; transitou basicamente polos vieiros da Lingüística, e, como lingüista foi -e é- un lingüista comprometido co seu problemático e aqueloutrado idioma. Foi, a partir de 1979, grosso modo, un lingüista sabio en case tódalas pólas da nosa Lingüística, e foi, asemade, o lingüista esperado e necesario. Para merecer esta consideración non basta co entusiasmo diario, coa entrega eficaz, coa dedicación íntima e teimuda; non basta co compromiso. En Antón Santamarina, ciencia e compromiso, saber e lealdade, rigor e solidariedade van de mans dadas.

De aí a grandeza e a densidade da súa obra de investigador e estudoso. Agora ben, o entusiasmo fondo e teimudo coa causa non lle impide albiscar, ás veces, que o futuro da lingua non se ofrece como luminoso. De novo, compromiso e ciencia de mans dadas.

Todo naceu, sen dúbida, o día en que oíu recitar a seu avó uns versos galegos de Curros Enríquez, uns versos escritos nun idioma que non era o dos señores, impresos nun libro que a familia ocultaba, despois de cada lectura, debaixo dunha pedra da cociña. A obra científica de Antón Santamarina, desde que se licenciou en Filoloxía Románica, foi, ó seu xeito, unha resposta a aquelas palabras, a aqueles prodixiosos versos e ó feito de que existían, na Galicia de Franco, na España de Franco, páxinas impresas que estaban prohibidas. 